\title{
Ontogenetic Changes of Ultrasonic Vocalizations Emitted from Infant Rats
}

\author{
Haruo HASHIMOTO ${ }^{1)}$, Naoki MORITANI'), Masahiro KATOU ${ }^{1)}$, \\ Takako NISHIYA ${ }^{2)}$, Pudcharaporn KROMKHUN ${ }^{3)}$, Makoto YOKOSUKA ${ }^{1)}$, \\ Minoru TANAKA ${ }^{2)}$, and Toru R. SAITO ${ }^{1)}$ \\ 1)Department of Comparative and Behavioral Medicine, 2)Department of Animal Physiology, \\ Nippon Veterinary and Life Science University, Tokyo 180-8602, Japan, and \\ ${ }^{3}$ Department of Physiology, Kasetsart University, Bangkok 10900, Thailand
}

\begin{abstract}
Ontogenetic changes of USVs were investigated to establish an index of stress in infant rats. The USVs were obtained by exposing infant rats to cold stress and were analyzed by real-time spectrography. USV waveforms consisted of four types, R-I, II, III and IV. These USVs were closely monitored at the age of 3-7 days in both sexes. From day 14, the frequency and incidence of USVs gradually decreased and had disappeared completely at the age of 21 days. Therefore, USVs should be useful in estimating the stress of infant rats between the ages of 3-7 days.
\end{abstract}

Key words: infant rats, ontogeny, ultrasound

Although prolactin [14], adrenal hormone [11], growth hormone [6, 8], and insulin [16] are physiological substances related to degrees of stress, biotic blood sampling from infant rodents has been impossible because of their very small body sizes. Stress of infant rodents depends on the nursing ability of the mother, breeding conditions and handling techniques [2, 3, 14]. It was reported that infant rodents emit ultrasonic vocalizations (USVs) when separated from the nest and at low temperatures [1]. Blumberg and Albert proposed that USVs under these conditions might merely be "an acoustic by-product" of a respiratory maneuver, elicited by decreased ambient temperature that functions physiologically [4]. Thus, the USV is a distress call from infant rodents, and we considered that USVs might become a standard of stress in infant rodents.

Rats (Rattus norvegicus; Wistar-Imamichi strain; seven litters), that had been raised in the authors' laboratory, were used for analysis of USVs at the ages of 0 , 1, 3, 7, 10, 14, 18 and 21 days. Their body weights are shown in Table 1. From each litter, two pups, one male and one female, were selected randomly for experiments. The lactating mothers were housed in polycarbonate cages $(220 \mathrm{D} \times 380 \mathrm{~W} \times 200 \mathrm{H} \mathrm{mm})$, and provided with exclusive feed for laboratory animals (MB-1; produced by Funabashi Farm Co., Ltd., Chiba, Japan) and tap water ad libitum. The animal room was maintained at a temperature of $24 \pm 2{ }^{\circ} \mathrm{C}$, relative humidity of $55 \pm 10 \%$, and 12-h artificial lighting from 07:00 to 19:00. The Animal Committee of Nippon

(Received 26 February 2007 / Accepted 23 April 2007)

Address corresponding: T.R. Saito, Department of Comparative and Behavioral Medicine, Nippon Veterinary and Life Science University, 1-7-1 Kyonan-cho, Musashino-shi, Tokyol80-8602, Japan 
Table 1. Ontogenetic body weights of the inflant rats used in this study

\begin{tabular}{lcc}
\hline & \multicolumn{2}{c}{ Body weights $(\mathrm{g})$} \\
\hline & \multicolumn{1}{c}{ Male } & Female \\
\cline { 2 - 3 } Day 0 & $6.2(0.1)^{1)}$ & $5.8(0.1)$ \\
Day 1 & $7.2(0.2)$ & $6.6(0.1)$ \\
Day 3 & $9.4(0.2)$ & $8.6(0.1)$ \\
Day 7 & $16.9(0.3)$ & $15.3(0.3)$ \\
Day 10 & $24.0(0.3)$ & $21.7(0.4)$ \\
Day 14 & $33.3(0.4)$ & $31.2(0.6)$ \\
Day 18 & $41.2(0.5)$ & $37.9(0.7)$ \\
Day 21 & $50.7(0.6)$ & $47.6(0.9)$ \\
\hline
\end{tabular}

1) Mean (SE).
Table 2. Changes of temperature on the bottom of the glass beaker used for isolation

\begin{tabular}{lcc}
\hline & \multicolumn{2}{c}{ Temperature $\left({ }^{\circ} \mathrm{C}\right)$ of cold stress } \\
\hline & Start $(0 \mathrm{~min})$ & End $(5 \mathrm{~min})$ \\
\hline Day 0 & $16.7(16.4-17.1)^{1)}$ & $14.1(13.4-14.7)$ \\
Day 1 & $16.4(16.2-17.0)$ & $13.9(13.6-14.9)$ \\
Day 3 & $16.4(15.8-17.1)$ & $13.9(13.1-14.6)$ \\
Day 7 & $16.5(16.3-16.8)$ & $13.8(13.5-14.4)$ \\
Day 10 & $16.1(15.9-16.5)$ & $13.8(13.3-14.2)$ \\
Day 14 & $16.6(16.3-17.0)$ & $14.0(13.6-15.0)$ \\
Day 18 & $16.7(16.4-17.0)$ & $13.8(13.5-15.1)$ \\
Day 21 & $16.4(16.4-17.0)$ & $13.7(13.4-14.1)$ \\
\hline
\end{tabular}

${ }^{1)}$ Median (minimum-maximum).
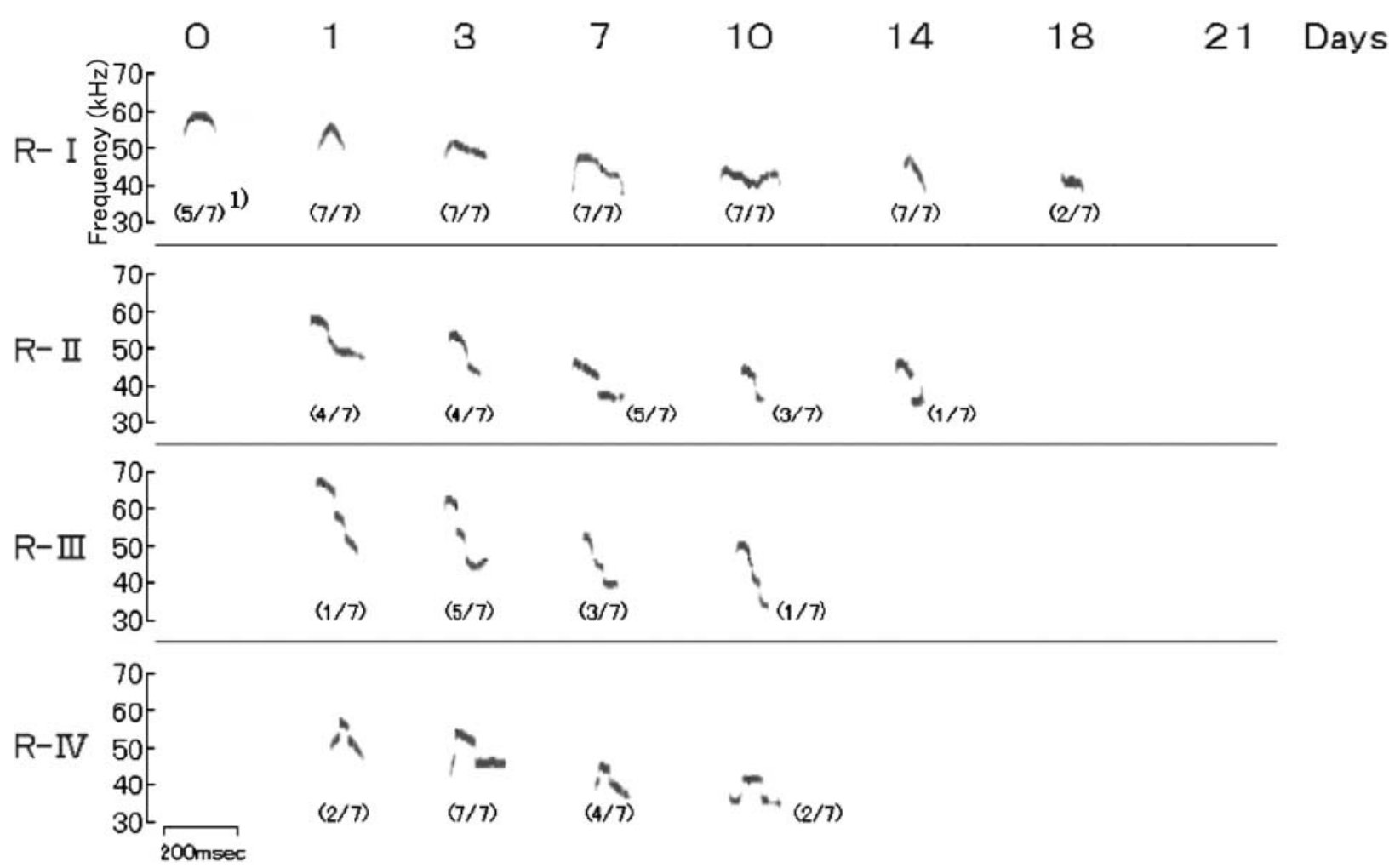

Fig. 1. Waveforms, frequencies and incidences of USVs emitted from male infant rats. ${ }^{1}$ No. of infants with USVs / No. of infants examined.

Veterinary and Life Science University approved this study. The infants were placed in a 500-ml glass beaker in isolation. Then, the glass beaker was placed on an ice bag $\left(15 \pm 2^{\circ} \mathrm{C}\right)$ in an incubator to attenuate ambient sounds for $5 \mathrm{~min}$. The temperature of the beaker bottom was measured using a thermo-hygrometer (TRH$\mathrm{CZ}$; SHINEI). Changes of temperature on the bottom of the glass beaker were examined at the start $(0 \mathrm{~min})$ and end ( $5 \mathrm{~min})$ of the measurement (Table 2). Instruments to collect USVs of the infant rodents were arranged as follows: A condenser microphone (Kunitachi Acoustic Lab., SF-12DC No.1730) was located 5 to $7 \mathrm{~cm}$ above the pups in the glass beaker. The microphone was connected to a computer with a 

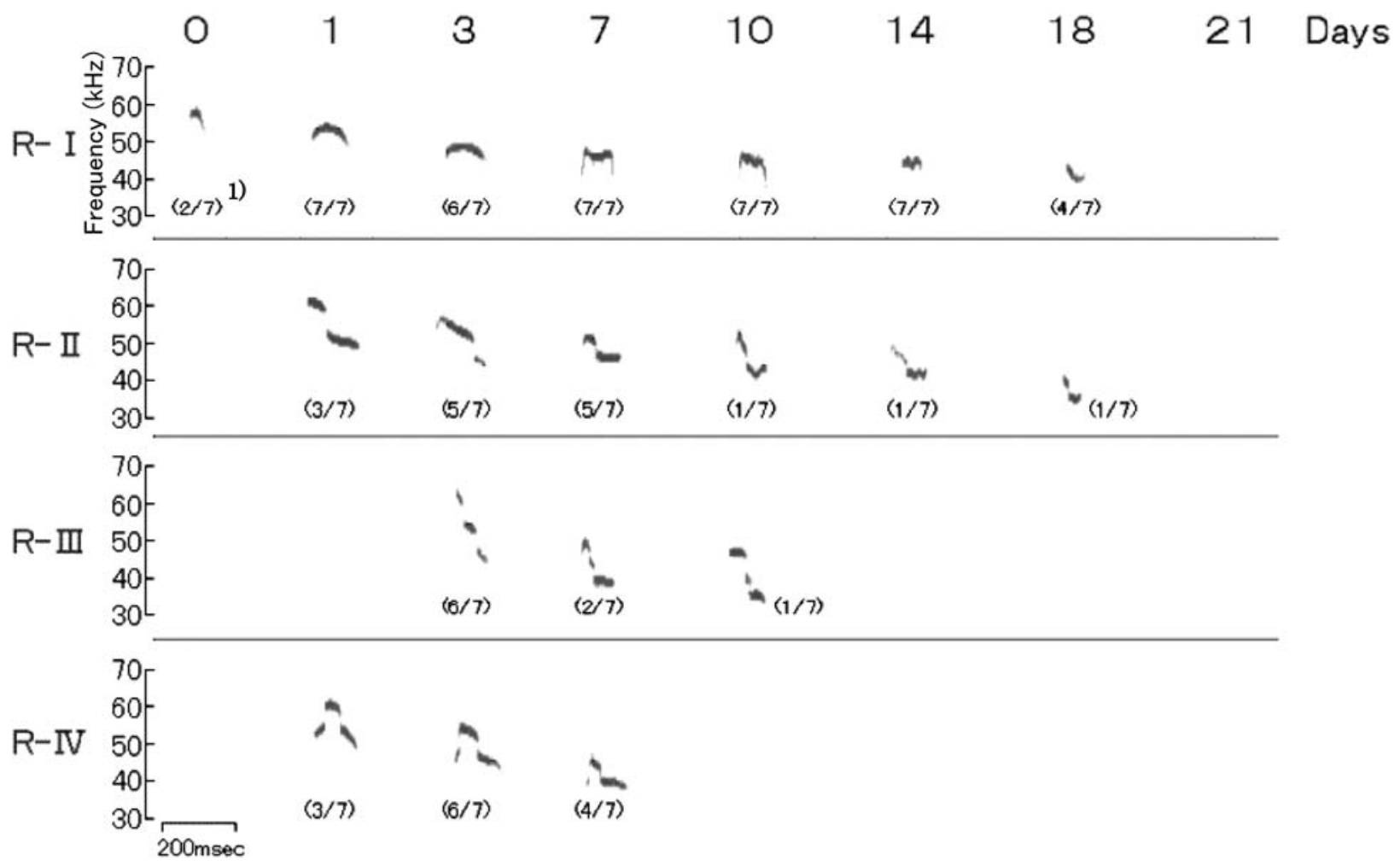

Fig. 2. Waveforms, frequencies and incidences of USVs emitted from female infant rats. ${ }^{1)}$ No. of infants with USVs / No. of infants examined.

real-time spectrograph (Engineering Design RTS) and a microphone amplifier (DIA Medical System) to eliminate noises and echoes from sampled USVs. The frequency response of the microphone was within \pm 0.5 $\mathrm{dB}$ in the frequency range from $5 \mathrm{~Hz}$ to $100 \mathrm{kHz}$. USVs obtained from infant rats were transformed to power spectra by a computer installed with SIGNAL software (Engineering Design) [9].

Types and incidences of USVs from male and female infants during nursing are shown in Figs. 1 and 2, respectively. The USVs emitted from the infant rats were of four types, R-I, R-II, R-III and R-IV, during the weaning period. The type of USV observed in infant rats at the age of 0 day was R-I. Between the ages of 1-7 days, the types and incidences of USV observed increased in both males and females. The incidences of R-I between the ages of 10-14 days were similar to those on other days, although the frequency was lower and the waveforms were smaller than those between the ages of 3-7 days. However, the incidences of other USVs, R-II, R-III and R-IV, gradually de- creased between the ages of 10-18 days, and at the age of 21 days, USVs emitted from infant rats had disappeared completely.

In this study, ontogenetic changes of USVs emitted from infant rats were investigated from birth to weaning. As Hashimoto et al. showed in a previous study [9], four types of USVs, R-I, II, III and IV, were observed, and their frequencies decreased in relation to the growth of the animals. The emission of USVs begins when brown adipose tissue (BAT) of infant rats begins producing heat, and oxygen consumption and respiratory rate also increase at this time [5]. The expiratory duration is prolonged because of laryngeal constriction, reducing airflow, and intrathoracic pressure increases [5, 12]. USV emission occurs as air passes through the constricted plate of the larynx [13]. BAT activity, which is induced by cold stress, is controlled by the autonomic nervous system $[10,15]$, the development of which is promoted by thyroid hormones in infant rats [7]. Therefore, the increased incidences and ontogenetic changes of USVs from day 0 to day 3 
might depend on the development of the laryngeal nerve in the nervous system. During weaning, frequencies of USVs decreased in inverse relation to growth, and the changes in USVs might be related to growth through the appearance of fur, or resistance to cold stress. Therefore, we consider that USVs would be useful for estimating stress in infant rats between the ages of 3-7 days. Further investigations on the relationship between waveforms of USVs and the degree of stress are warranted.

\section{Acknowledgment(s)}

The authors are grateful to Assistant Professor Dr. Y. Kondo, Department of Physiology, Nippon Medical School, Tokyo, Japan, for his helpful advice.

\section{References}

1. Allin, J.T. and Banks, E.M. 1971. Dev. Psychobiol. 4: 149156.

2. Balcombe, J.P., Barnard, N.D., and Sandusky, C. 2004. Contemp. Top. Lab. Anim. Sci. 43: 42-51.
3. Bell, R.W., Nitschke, W., Gorry, T.H., and Zachman, T.A. 1971. Dev. Psychobiol. 4: 181-191.

4. Bell, R.W., Nitschke, W., and Zachman, T.A. 1972. Behav. Biol. 7: 805-814.

5. Blumberg, M.S. and Alberts, J.R. 1990. Behav. Neurosci. 104: 808-817.

6. Calvino, B., Besson, J.M., Mounier, F., Kordon, C., and Bluet-Pajot, M.T. 1992. Pain 49: 27-32.

7. Eayrs, J.T. 1966. Sci. Basis. Med. Annu. Rev. 3: 17-39.

8. Eck, J.B. and Kuhn, C.M. 1992. Neuroendocrinology 56: 605-610.

9. Hashimoto, H., Moritani, N., Aoki-Komori, S., Tanaka, M., and Saito, T.R. 2004. Exp. Anim. 53: 409-416.

10. Kawate, R., Talan, M.I., and Engel, B.T. 1994. Physiol. Behav. 55: 921-925.

11. Meijer, M.K., Lemmens, A.G., Van Zutphen, B.F., and Baumans, V. 2005. J. Appl. Anim. Welf. Sci. 8: 279-283.

12. Roberts, L.H. 1972. J. Zool. Lond. 168: 439-449.

13. Roberts, L.H. 1975. Ultrasonics 13: 83-88.

14. Severino, G.S., Fossati, I.A., Padoin, M.J., Gomes, C.M., Trevizan, L., Sanvitto, G.L., Franci, C.R., Anselmo-Franci, J.A., and Lucion, A.B. 2004. Physiol. Behav. 81: 489-498.

15. Wetzel, D.M., Kelley, D.B., and Campbell, B.A. 1980. J. Comp. Physiol. Psychol. 94: 596-605.

16. Zardooz, H., Zahedi, A.S., and Naseri, M.G. 2006. Life Sci. 79: 57-62. 